\title{
Diving behavior and swimming style of nursing bearded seal pups
}

\author{
Yuuki Watanabe ${ }^{1,2, *}$, Christian Lydersen ${ }^{3}$, Katsufumi Sato ${ }^{1}$, Yasuhiko Naito ${ }^{2}$, \\ Nobuyuki Miyazaki ${ }^{4}$, Kit M. Kovacs ${ }^{3}$ \\ ${ }^{1}$ International Coastal Research Center, Ocean Research Institute, The University of Tokyo, 2-106-1 Akahama, Otsuchi, \\ Iwate 028-1102, Japan \\ ${ }^{2}$ National Institute of Polar Research, 1-9-10 Kaga, Itabashi, Tokyo 173-8515, Japan \\ ${ }^{3}$ Norwegian Polar Institute, N-9296 Tromsø, Norway \\ ${ }^{4}$ Ocean Research Institute, The University of Tokyo, 1-15-1 Minamidai, Nakano, Tokyo 164-8639, Japan
}

\begin{abstract}
Seals are born on land or ice and must acquire the diving and swimming skills required to forage and avoid predators during their early lives. While diving behavior, including swim speed and swimming style (e.g. prolonged gliding and stroke-and-glide swimming), of adult seals is well documented, knowledge regarding the diving behavior of pups is still limited to records of dive depth and duration measured by simple time-depth recorders. In the present study, we attached multisensor data loggers to 6 bearded seal Erignathus barbatus pups weighing between $33 \mathrm{~kg}$ (newborn) and $104 \mathrm{~kg}$ (close to weaning). The mean swim speed and the mean distance covered by a stroke cycle was lowest $\left(0.5 \mathrm{~m} \mathrm{~s}^{-1}\right.$ and $0.3 \mathrm{~m}$, respectively) in the smallest pup and highest $\left(0.9 \mathrm{~m} \mathrm{~s}^{-1}\right.$ and $0.6 \mathrm{~m}$ ) in the largest pup. The largest pup showed substantial periods (17\% of transit time) of prolonged gliding, as adult seals commonly do. However, the 3 medium-sized pups glided only during $<5 \%$ of the transit time, and the 2 smallest pups did not glide. Stroke-and-glide swimming was not observed in any pups. The stroke cycle frequency of the smallest pup was highly variable, while that of the largest pup was relatively stable. These results suggest that the swimming performance of the pups developed during the short nursing period.
\end{abstract}

KEY WORDS: Data logger $\cdot$ Release system $\cdot$ Accelerometer $\cdot$ Development $\cdot$ Spectrogram $\cdot$ Power spectral density $\cdot$ Bandwidth $\cdot$ Erignathus barbatus

Resale or republication not permitted without written consent of the publisher

\section{INTRODUCTION}

Phocids (true seals) breed on land or ice, and the pups enter the water and start foraging either during lactation periods (4 to $90 \mathrm{~d}$ ) or following a period of post-weaning fast (weeks or months). Because this transition from the terrestrial to the aquatic environment is critical for survival (Le Boeuf et al. 1994), knowledge of the diving behavior of pups is essential for our understanding of the ecology of seals.

Dives of pups are shallower and shorter than those of adults (Gjertz et al. 2000). This is presumably because the pups are still developing in terms of their physiology (e.g. oxygen store) and behavior (e.g. swimming skills).
The physiological features with regard to diving are well studied, and pups are known to have smaller massspecific oxygen stores than adults (Burns et al. 2005, 2007). Additionally, pups have higher mass-specific resting metabolic rates (Rea \& Costa 1992, Burns et al. 2005) and poorer heart-rate control during diving than adults (Greaves et al. 2004); these likely increase the costs of diving in pups and thus limit their diving capabilities.

In contrast, little is known about the behavioral features of seal pups with regard to diving. For example, adults commonly adopt various swimming styles such as prolonged gliding and stroke-and-glide swimming (Williams et al. 2000, Davis et al. 2001, Sato et al. 2003, Watanabe et al. 2006); however, whether pups can use 
these styles is not clear. Furthermore, the swimming stroke activity of pups may be less stable and less efficient than adults, as is the case in the locomotory abilities of humans (Hausdorff et al. 1999). To test these predictions, it is necessary to monitor the stroke activity of pups using accelerometers (Sato et al. 2003), video cameras (Williams et al. 2000), or magnetic sensors (Wilson \& Liebsch 2003).

Bearded seal Erignathus barbatus pups enter the water within a few hours of birth (Kovacs et al. 1996), possibly to avoid predators such as polar bears, and can be expected to demonstrate immature diving behavior more clearly than other species. In the present study, we deployed multi-sensor data loggers that recorded depth, swim speed, and acceleration on bearded seal pups weighing between $33 \mathrm{~kg}$ (newborn) and $104 \mathrm{~kg}$ (close to weaning). The objective of the present study was to determine the characteristics of diving behavior and swimming style of pups. By comparing these characteristics to the general pattern of adults, insights can be gained into the development of diving behavior in seals.

\section{MATERIALS AND METHODS}

Study sites and seals. Field experiments were conducted in Kongsfjorden $\left(78.9^{\circ} \mathrm{N}, 12.5^{\circ} \mathrm{E}\right)$, Svalbard, Norway, in May 2006 and May 2007. The study periods covered the peak birthing period of bearded seals in Svalbard (the first week of May) and the subsequent lactation period that lasts about $3 \mathrm{wk}$ (Lydersen \& Kovacs 1999). Mother-pup pairs that were resting on ice floes or swimming were approached by boat, and 6 pups were captured using a custom-built dip net. The pups were weighed using a Salter spring scale $( \pm 0.5 \mathrm{~kg})$, and their sex was determined. They were then instrumented (see next paragraph) and released. All the mothers remained in the water nearby during the entire procedure, and approached their pups and swam with them upon their release. This protocol was approved by the Governor of Svalbard (Sysselmannen) and the Norwegian Animal Research Authority. The ages (days) of 3 of the pups were known because their birth dates were known from daily censuses. The ages of the other 3 pups were estimated from their body mass, assuming a daily mass gain of $3.3 \mathrm{~kg}$ (Lydersen et al. 1994) and a newborn body mass of $38 \mathrm{~kg}$ (K. M. Kovacs \& C. Lydersen unpubl. data) (see Table 1).

Instruments. We used $512 \mathrm{Mb}$ W2000L-PD2GT data loggers (length $=127 \mathrm{~mm}$, diameter $=27 \mathrm{~mm}$, weight in air $=125 \mathrm{~g}$; Little Leonardo), which recorded swim speed, depth, and temperature at $1 \mathrm{~s}$ intervals, and 2-dimensional (lateral and longitudinal) accelerations at $1 / 32 \mathrm{~s}$ intervals. The maximum range of the depth sensor was $2000 \mathrm{~m}$, with a resolution of $0.5 \mathrm{~m}$. Data loggers must be recovered to obtain the data, but recapture of the instrumented seals is difficult. Therefore, we used a newly developed remote-controlled release system that enabled the logger to be retrieved without recapture of the animals (Fig. 1). A mat of synthetic fibers was glued onto the fur on the back of the seals with a quick-setting epoxy resin. Then, a package composed of a data logger, a release mechanism with a semi-rigid antenna for UHF radio signals (Little Leonardo), and a float of copolymer foam (Nichiyu Giken Kogyo) was attached to the mat with a plastic cable. The cable was connected to the release mechanism. When the seals were located some days after the initial deployment, UHF radio signals were sent by a transmitter to activate the release mechanism from a distance of about $50 \mathrm{~m}$. The cable was severed by an electric charge from the battery of the mechanism, and the package was released from the seal. The package also contained a VHF transmitter (Telonics) that helped in locating the seals. The total weight of the instruments was $288 \mathrm{~g}$ in air ( 0.3 to $0.9 \%$ of the body mass of the seals) and its buoyancy offset $56 \mathrm{~g}$ in water.

Data analysis. Based on the absolute accuracy of the sensor, a dive was defined as any excursion below the sea surface to a depth of $>2 \mathrm{~m}$. The diving capability of

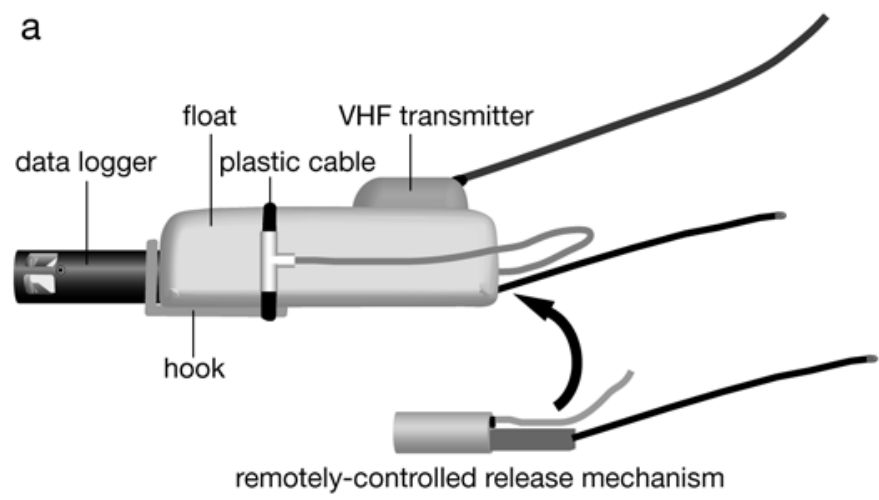

b

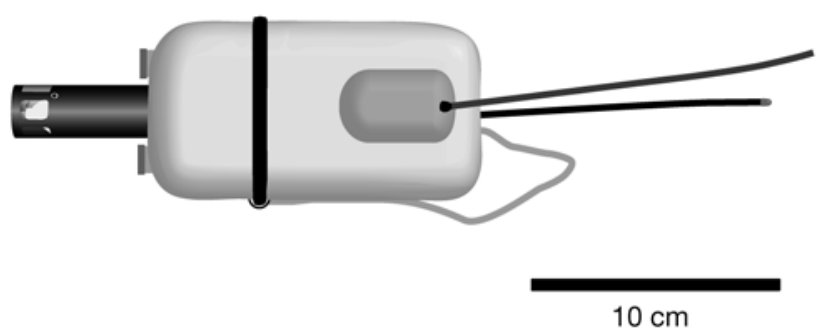

Fig. 1. (a) Side and (b) top views of the remote-release package containing the data logger. The release mechanism is set into the float upon deployment 
the pups was first examined by their dive depths and durations. To examine their swimming behavior in greater detail, each dive was subdivided into a descent phase (from the beginning of a dive to the time of the first ascent), an ascent phase (from the time of the last descent to the end of the dive), and a bottom phase (the time between the end of descent and the beginning of ascent). We excluded dives in which the depth at the start or end of the bottom phase was $<5 \mathrm{~m}$, because swimming parameters (e.g. speed and number of strokes) measured over very short descent or ascent are not reliable.

The relative swim speed through water was recorded as the number of rotations per second (rps) of an external propeller mounted at the anterior end of the loggers. This value was converted to the actual swimming speed $\left(\mathrm{m} \mathrm{s}^{-1}\right)$ using the calibration method of Sato et al. (2003).

From lateral acceleration records, we extracted information on stroke activity of the seals by filtering out the low-frequency signals with IGOR Pro (WaveMetrics) (Sato et al. 2003). A single stroke cycle was defined as the period taken by the flipper to move from one extreme lateral position back to the original position. Gliding was defined as the period when the seals stop stroking for more than $2 \mathrm{~s}$, which corresponded to approximately twice the mean duration of the stroke cycle for all pups. Distance covered by a stroke cycle $(\mathrm{m})$ was calculated as the swim speed $\left(\mathrm{m} \mathrm{s}^{-1}\right)$ integrated over a period (s) divided by the number of strokes during the period.

Modulation of the stroke activity was first visualized by creating the Gabor spectrograms for filtered lateral acceleration with IGOR Pro (Sato et al. 2008). Then, the variability of the stroke cycle frequency within individuals was quantified by determining bandwidth, which represents the deviations around the centroid frequency and is usually used for acoustic data (e.g. Madsen et al. 2004). To obtain bandwidth, power spectral density (PSD) of lateral acceleration was calculated by fast Fourier transformation with IGOR Pro. PSD showed the peak frequency that represented the dominant stroke cycle frequency of each seal (Sato et al. 2007). Bandwidth of the signals was calculated as the range of frequencies where the power of the fast Fourier transformation was above $95 \%$ of the maximum value. This value $(95 \%)$ was chosen because it gave the maximum bandwidth excluding the lowfrequency signals, which are assumed to be the result of turning and rolling movements of the seals.

A single-factor ANOVA followed by Scheffe's posthoc test was performed with StatView (SAS Institute) to compare diving (e.g. dive depth) and swimming parameters (e.g. speed) among individuals. Because successive dives made by 1 individual can be auto- correlated, we also randomly selected 110 and 50 dives (i.e. the lowest number of dives recorded for 1 individual) from each seal for the analyses of diving and swimming parameters, respectively, and performed the same tests. The value for statistical significance was set at $\mathrm{p}<0.05$. Mean $\pm \mathrm{SD}$ values are reported.

\section{RESULTS}

Behavior was recorded for approximately $3 \mathrm{~d}$ (63 to $78 \mathrm{~h}$ ) for each pup, except for the largest pup, in which the data logger was accidentally lost $3 \mathrm{~h}$ after deployment and recovered from the sea surface the following day (Table 1). The pups spent an average of $58 \pm 12 \%$ $(n=5)$ of their time hauled out on the ice and the rest of their time in the water, excluding the largest pup, which was in the water throughout the $3 \mathrm{~h}$ recording period. The smallest pup showed the highest haul-out time $(78 \%)$, and its daily haul-out time decreased continuously from 84 to $73 \%$ during the $3 \mathrm{~d}$. A total of 5518 dives were recorded for the 6 pups. The dives of the smallest pup were the shallowest (ANOVA, $F_{5,5512}=27.5, \mathrm{p}<0.0001 ;$ Scheffe's post-hoc test, $\mathrm{p}<$ 0.0001 for all 5 combinations) and the shortest if excluding the largest pup $\left(F_{5,5512}=40.8, \mathrm{p}<0.0001 ; \mathrm{p}<\right.$ 0.0001 for 4 combinations), a result probably affected by the short recording period for the largest pup. Tests using 660 randomly-selected dives (110 dives for each seal) gave the same results, except that dive depth of the smallest pup did not differ significantly from 2 medium-sized pups (Eb-07-26 and Eb-06-02), and dive duration of the smallest pup did not differ significantly from one of the medium-sized pups (Eb-07-26). All the diving parameters (i.e. daily mean and maximum dive depth and duration) increased continuously only in the smallest pup. All pups showed dives with a bottom phase during which the swim speed dropped below the stall speed of the sensor. Such dives constituted $26 \pm 14 \%(\mathrm{n}=6)$ of the total number of dives (Table 1).

We selected 2146 dives for the analysis of swimming behavior (Table 1). Swim speed during transit phases (i.e. descents and ascents) was the lowest in the smallest $\operatorname{pup}\left(F_{5,2140}=83.4, \mathrm{p}<0.0001 ; \mathrm{p}<0.0001\right.$ for all 5 combinations) and highest in the largest pup (Scheffe's posthoc test, $\mathrm{p}<0.0001$ for all 5 combinations). Distance covered by a stroke cycle during transit phases was the lowest in the smallest pup $\left(F_{5,2140}=227, \mathrm{p}<0.0001\right.$; Scheffe's post-hoc test, $\mathrm{p}<0.0001$ for all the 5 combinations) and the highest in the largest pup (Scheffe's posthoc test, $\mathrm{p}<0.0001$ for all 5 combinations). Tests using 300 randomly-selected dives (50 dives for each seal) gave the same results. The 2 smallest pups stroked continuously throughout both descent and ascent (Fig. 2a). 


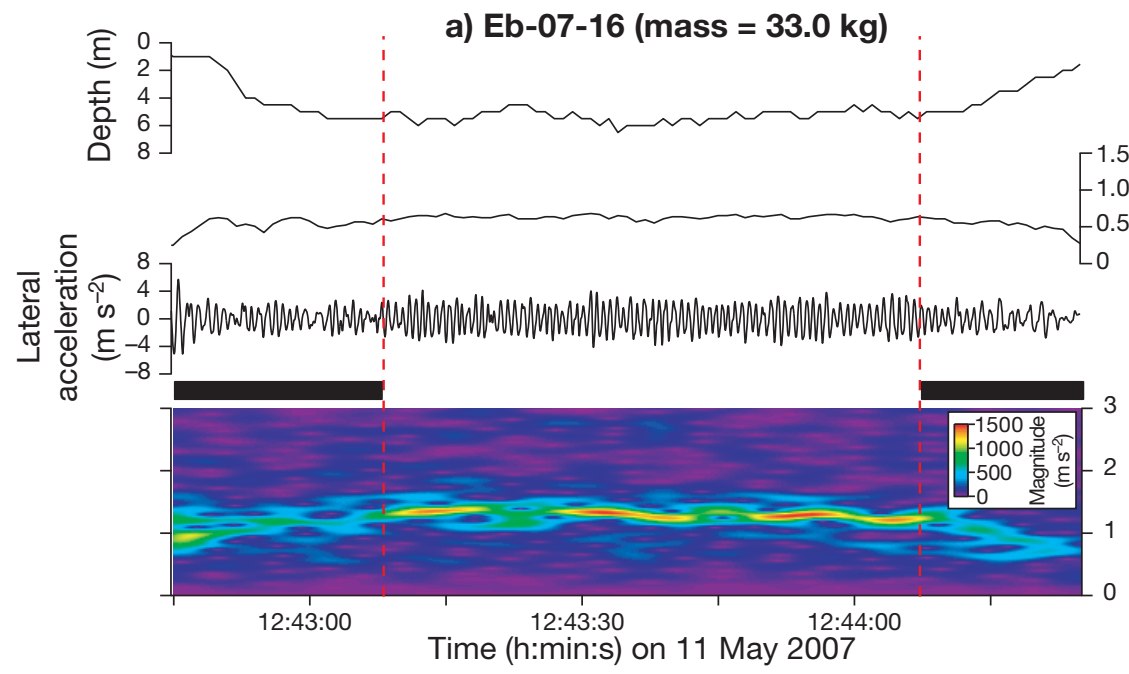

b) Eb-06-02 (mass = $49.5 \mathrm{~kg})$ In
के
0
0
0
0
के

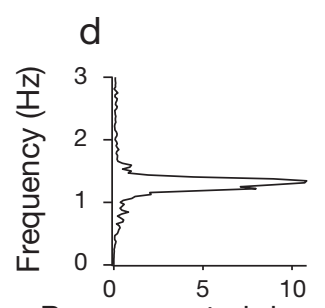

Power spectral density $\left(\left[\mathrm{m} \mathrm{s}^{-2}\right]^{2} \mathrm{~Hz}^{-1}\right)$

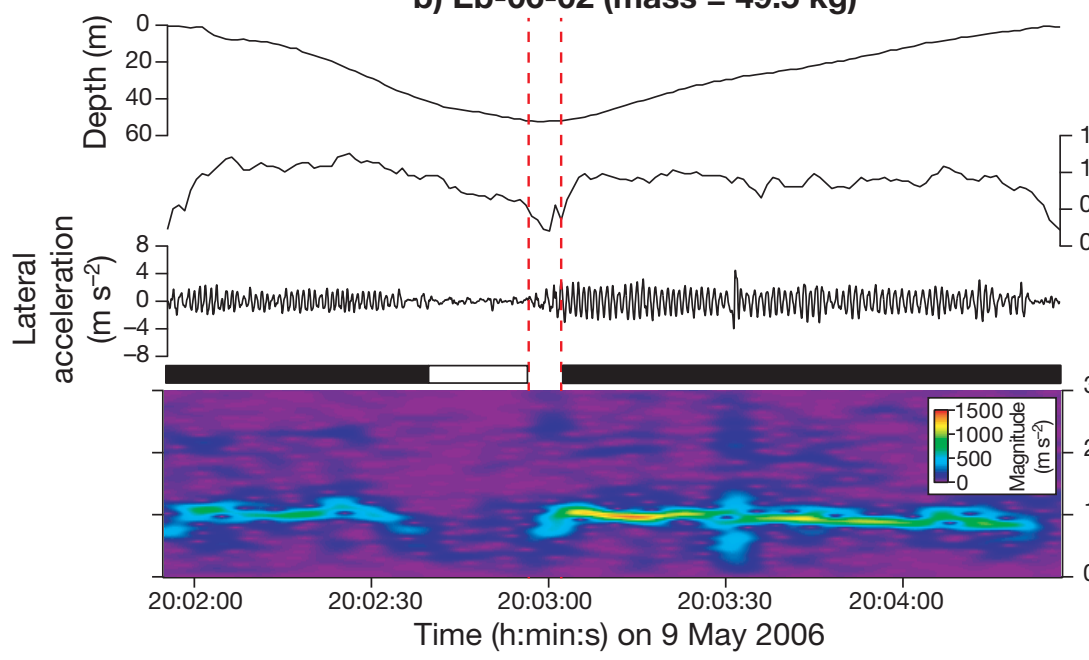

c) Eb-07-04 (mass = 104.0 kg)

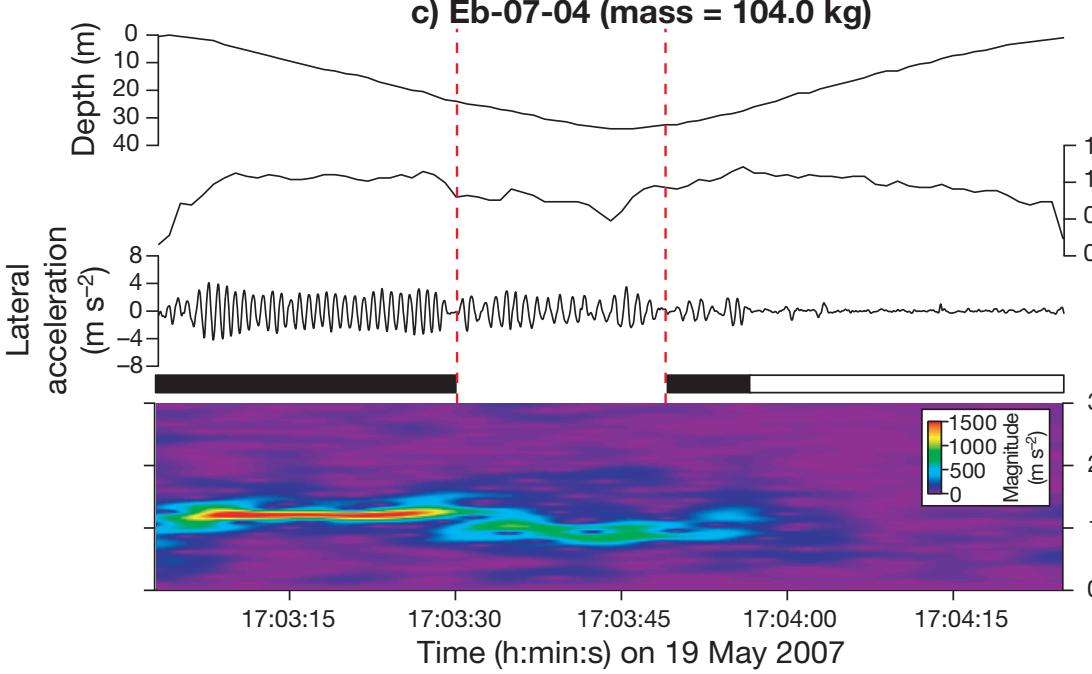

To छ की

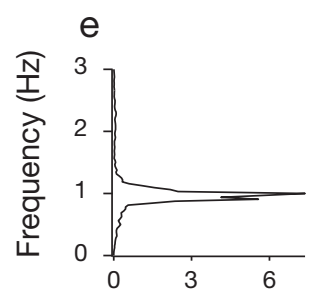

Power spectral density $\left(\left[\mathrm{m} \mathrm{s}^{-2}\right]^{2} \mathrm{~Hz}^{-1}\right)$

\section{in क}

1.0 ह

5 ఫ

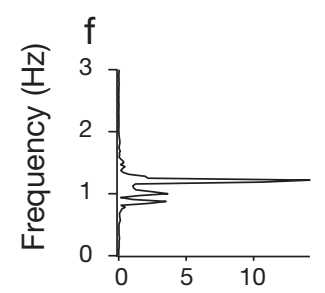

Power spectral density $\left(\left[\mathrm{m} \mathrm{s}^{-2}\right]^{2} \mathrm{~Hz}^{-1}\right)$

Fig. 2. Erignathus barbatus. Single dives made by pups (a) Eb-07-16, (b) Eb-06-02, and (c) Eb-07-04 with depth, swim speed, filtered lateral acceleration (indicative of stroke activity), and a spectrogram of filtered lateral acceleration where magnitude was expressed by color. Red vertical dashed lines delimit 3 dive phases: descent, bottom, and ascent; : continuous strokes; 
Table 1. Erignathus barbatus. Diving and swimming behavior of bearded seal pups. Individuals are shown in order of weight. Means \pm SD are presented

\begin{tabular}{|c|c|c|c|c|c|c|}
\hline \multirow{2}{*}{ Attribute } & \multirow[b]{2}{*}{ Eb-07-16 } & \multirow[b]{2}{*}{ Eb-07-19 } & \multicolumn{2}{|c|}{ - Pup identification $\longrightarrow$} & \multirow[b]{2}{*}{ Eb-06-04 } & \multirow[b]{2}{*}{ Eb-07-04 } \\
\hline & & & $\mathrm{Eb}-07-26$ & Eb-06-02 & & \\
\hline \multicolumn{7}{|l|}{ Descriptive information } \\
\hline Sex & $\mathrm{M}$ & $\mathrm{M}$ & $\mathrm{F}$ & $\mathrm{M}$ & $\mathrm{M}$ & M \\
\hline Date of capture & 10 May 2007 & 13 May 2007 & 16 May 2007 & 9 May 2006 & 9 May 2006 & 19 May 2007 \\
\hline Body mass at capture $(\mathrm{kg})$ & 33.0 & 44.0 & 49.0 & 49.5 & 58.5 & 104.0 \\
\hline Age at capture $(\mathrm{d})$ & 0 & $2^{\mathrm{a}}$ & $3^{\mathrm{a}}$ & 5 & $6^{\mathrm{a}}$ & 17 \\
\hline \multicolumn{7}{|l|}{ Diving behavior } \\
\hline Data length (h) & 70 & 63 & 69 & 78 & 70 & 3 \\
\hline Haul-out time (\%) & 78 & 45 & 51 & 57 & 60 & 0 \\
\hline No. of dives & 620 & 1483 & 1527 & 905 & 873 & 110 \\
\hline $\begin{array}{l}\text { Dives with bottom phase } \\
\text { where speed drops (\%) }\end{array}$ & 21 & 12 & 16 & 47 & 38 & 23 \\
\hline \multicolumn{7}{|l|}{ Dive depth (m) } \\
\hline mean & $5 \pm 2$ & $8 \pm 5$ & $8 \pm 8$ & $8 \pm 8$ & $9 \pm 9$ & $9 \pm 8$ \\
\hline maximum & 16 & 32 & 74 & 54 & 69 & 48 \\
\hline \multicolumn{7}{|l|}{ Dive duration (min) } \\
\hline mean & $0.5 \pm 0.4$ & $0.7 \pm 0.5$ & $0.7 \pm 0.7$ & $0.9 \pm 0.8$ & $0.8 \pm 0.7$ & $0.5 \pm 0.4$ \\
\hline maximum & 2.8 & 2.9 & 4.3 & 3.8 & 3.3 & 2.1 \\
\hline \multicolumn{7}{|l|}{ Swimming behavior } \\
\hline No. of dives selected & 122 & 728 & 633 & 252 & 361 & 50 \\
\hline \multicolumn{7}{|l|}{ Swim speed $\left(\mathrm{m} \mathrm{s}^{-1}\right)$} \\
\hline mean & $0.5 \pm 0.1$ & $0.8 \pm 0.1$ & $0.8 \pm 0.1$ & $0.7 \pm 0.2$ & $0.8 \pm 0.2$ & $0.9 \pm 0.2$ \\
\hline maximum & 0.9 & 1.4 & 1.6 & 1.6 & 1.8 & 1.6 \\
\hline Glide time (\%) & $1 \pm 2$ & $1 \pm 3$ & $1 \pm 2$ & $5 \pm 5$ & $2 \pm 3$ & $17 \pm 10$ \\
\hline $\begin{array}{l}\text { Distance covered } \\
\text { by a stroke cycle (m) }\end{array}$ & $0.3 \pm 0.0$ & $0.4 \pm 0.1$ & $0.4 \pm 0.1$ & $0.4 \pm 0.1$ & $0.4 \pm 0.1$ & $0.6 \pm 0.1$ \\
\hline $\begin{array}{l}\text { Dominant stroke } \\
\quad \text { cycle frequency }(\mathrm{Hz})\end{array}$ & 1.0 & 1.2 & 1.0 & 0.9 & 1.0 & 1.2 \\
\hline Bandwidth (Hz) & 0.27 & 0.13 & 0.10 & 0.13 & 0.15 & 0.04 \\
\hline aAge estimated from weight & & & & & & \\
\hline
\end{tabular}

Three of the medium-sized pups (Eb-07-26, Eb-06-02, and Eb-06-04) glided during the last part of the descent of deep dives (>40 m) (Fig. 2b). However, gliding was not the main swimming style for any of the medium-sized pups; mean glide time during transit phases constituted only 1 to $5 \%$ of the transit time (Table 1 ). In contrast, the largest pup glided during most of the ascent (Fig. 2c), and its gliding time during transit phases was by far the highest $\left(F_{5,2140}=257, \mathrm{p}<0.0001 ; \mathrm{p}<0.0001\right.$ for all 5 combinations) (Table 1). A test using 300 randomly-selected dives (50 dives for each seal) gave the same result. Stroke-and-glide swimming was not observed in any pups.

Spectrograms showed different modulation patterns of the stroke activity among the pups (Fig. 2a-c). The stroke cycle frequency of the largest pup during descent was stable at $1.2 \mathrm{~Hz}$, while that of the smallest pup was more variable. The 4 medium-sized pups showed intermediate patterns between the smallest and largest pups. These differences in the spectrograms corresponded to the differences in the PSD profiles calculated for each dive (Fig. $2 \mathrm{~d}-\mathrm{f}$ ). The slopes around the peak, which corresponded to the dominant stroke cycle frequency of the dive, were steep in the largest pup and gentle in the smallest pup, indicating higher stability in stroke cycle frequency in the largest pup. The examples in Fig. 2 show that the width of the peak band on the PSD profiles is a good indicator of the variability in the stroke cycle frequency; these findings support our application of bandwidth to acceleration data. The PSD profiles of the entire lateral acceleration records differed qualitatively among the pups (Fig. 3). In the smallest pup, no specific peak was evident and the slope was gradual, showing the highest bandwidth. In the largest pup, the peak was pronounced and the slope around the peak was steep, yielding the lowest bandwidth. The 4 medium-sized pups showed intermediate bandwidths (Table 1).

\section{DISCUSSION}

The pups spent approximately half of their time hauled out, and the other half in water; this was in agreement with Lydersen et al. (1994), who studied bearded seal pups weighing between 41 and $54 \mathrm{~kg}-\mathrm{a}$ 
narrower range than in the present study. However, the newborn in this study spent $84 \%$ of its time hauled out on the first day of life, and gradually decreased its daily haul-out time over the next $2 \mathrm{~d}$. Adult females of this species spend only $8 \%$ of their time hauled out during the nursing period, spending the majority of their time diving and remaining at the sea surface adjacent to the ice floes where their pups are resting (Krafft et al. 2000). Our results indicate that bearded seals begin to adopt a more aquatic lifestyle (i.e. less time on floating ice) during the early stages of life. Unlike most phocids, pups of this species start foraging before weaning (Lydersen et al. 1996). Because bearded seals prey on fishes, crustaceans, mollusks, and worms at the sea floor (Hjelset et al. 1999) using their sensitive whiskers (Marshall et al. 2006), the bottom phases where swim speeds drop suggest they are foraging. In the present study, all pups including the newborn demonstrated such dives. This suggests that the pups imitated the swimming behavior of the accompanying mothers, who frequently dive shallowly $(<10 \mathrm{~m})$ and forage during the nursing period (Krafft et al. 2000). Independent prey acquisition probably does not begin until after 1 or

a) Eb-07-16 (mass $=33.0 \mathrm{~kg}$ )

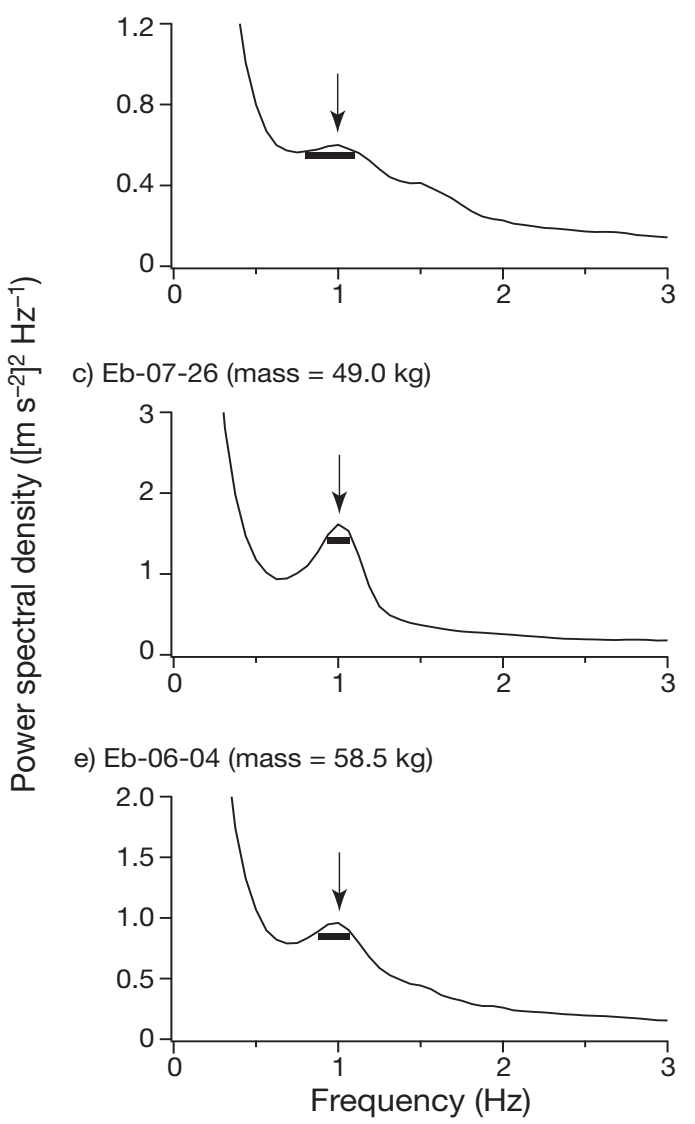

2 wk of life (K. M. Kovacs \& C. Lydersen unpubl. data).

The dive depths and durations recorded in the present study were similar to those previously reported for bearded seal pups (Lydersen et al. 1994) and were less than those of adults (Krafft et al. 2000). The dives of the newborn, in particular, were shallow and short. However, the diving capability of this pup increased on a daily basis, suggesting a rapid development of diving capabilities during early post-natal life.

The mean swim speed was the lowest $\left(0.5 \mathrm{~m} \mathrm{~s}^{-1}\right)$ in the smallest pup and the highest $\left(0.9 \mathrm{~m} \mathrm{~s}^{-1}\right)$ in the largest pup. The speed of the largest pup was similar to that of adult bearded seals (0.9 to $1.4 \mathrm{~m} \mathrm{~s}^{-1}$, Krafft et al. 2000). The increase in swim speed during the nursing period cannot be attributed to the increase in body length, which changes little during the first year of life (K. M. Kovacs \& C. Lydersen unpubl. data). Furthermore, neither muscle mass (as a percent of body mass) nor mass-specific oxygen stores increase during the nursing periods in seals (Burns et al. 2007). Therefore, the increase in speeds may have been achieved by experience or the development of neuromuscular coordination.

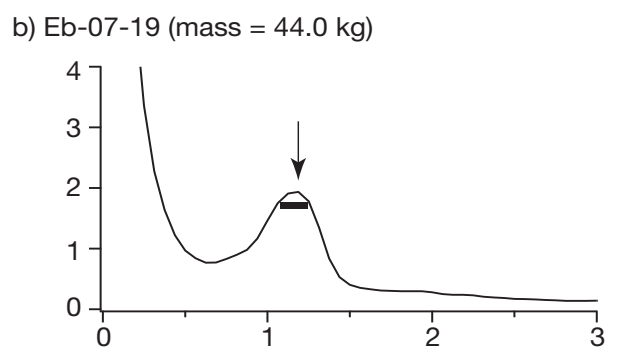

d) Eb-06-02 (mass $=49.5 \mathrm{~kg})$

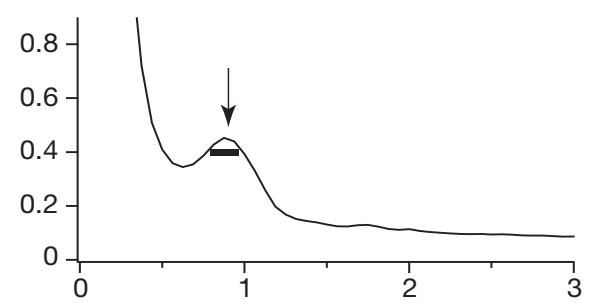

f) $\mathrm{Eb}-07-04$ (mass $=104.0 \mathrm{~kg})$

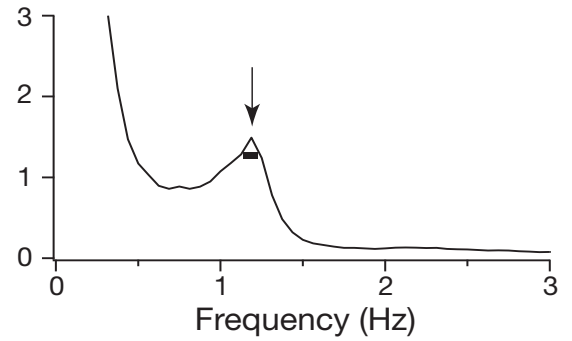

Fig. 3. Erignathus barbatus. Power spectral density calculated from the entire lateral acceleration records for each pup. Pups are shown in order of weight. - Bandwidth; arrows indicate dominant stroke cycle frequency 
Only the largest pup showed substantial periods of prolonged gliding, an efficient means of locomotion through water (Williams et al. 2000). The effectiveness of gliding was evident by the largest distance covered by a stroke cycle $(0.6 \mathrm{~m})$ of this pup. This pup, which was close to weaning, glided throughout ascent, indicating that gliding was assisted by positive buoyancy caused by the increase in the subcutaneous blubber layer during nursing (Biuw et al. 2003, Sato et al. 2003, Watanabe et al. 2006). In contrast, 3 of the mediumsized pups glided only during the last parts of descent in deep dives, when they were presumably negatively buoyant. The 2 smallest pups did not glide, suggesting that pups develop the ability to glide during the nursing period. No pups in this study showed stroke-andglide swimming, which is an efficient locomotory mode, at least in theory (Weihs 1974). Our results suggest that the swimming style of pre-weaned pups was immature, but it developed over the short nursing period.

Spectrograms and PSD profiles of lateral acceleration indicate that the stroke cycle frequency of the smallest pup was highly variable and that of the largest pup was relatively stable. Steady strokes are physiologically preferable for cruising because muscle contraction is most efficient over a narrow range of contraction speeds and loads (Hill 1950, 1964). In addition, steady swimming is physically advantageous because it decreases body inertia and acceleration reaction, which animals must work against (Webb 1988). Therefore, a decrease in the variability of the stroke cycle frequency presumably represents an improvement in the swimming performance. The shortest distance covered by a stroke cycle in the smallest pup $(0.3 \mathrm{~m})$ might be attributed to the largest variability in its stroke activity. A similar phenomenon is seen in human children with respect to the variability of stride duration, which decreases with age (Hausdorff et al. 1999). Until now, ontogeny of locomotor performance was studied only in humans (Hausdorff et al. 1999), captive animals (Noren et al. 2006), and wild animals under controlled conditions (Irschick 2000). Accelerometers provide a new tool for quantifying the developmental changes in locomotory performance in wild animals in their natural habitats.

In conclusion, the swimming performance of preweaned bearded seal pups was immature, but it developed during the short nursing period. The mean swim speed and the distance covered by a stroke cycle was lowest in the smallest pup and highest in the largest pup. Only the largest pup, which was close to weaning, showed substantial periods of gliding during ascent. Stroke-and-glide swimming was not observed in any pups. The stroke cycle frequency was highly variable in the smallest pup but relatively stable in the largest pup.
Acknowledgements. We thank M. Fedak, C. Freitas, M. Haupt, M. Hindell, and C. Marshall for their assistance with the fieldwork, T. Morisaka and K. Yoda for advice on data analysis, and P. Miller and 4 anonymous referees for helpful comments on the manuscript. This work was funded by the Norwegian Research Council, the Norwegian Polar Institute, the Japan Society for the Promotion of Science (A19255001), JSPS Research Fellowships for Young Scientists (Y.W.), and the program Bio-logging Science of The University of Tokyo (UTBLS).

\section{LITERATURE CITED}

Biuw M, McConnell B, Bradshaw CJA, Burton H, Fedak M (2003) Blubber and buoyancy: monitoring the body condition of free ranging seals using simple dive characteristics. J Exp Biol 206:3405-3423

> Burns JM, Costa DP, Frost KJ, Harvey JT (2005) Development of body oxygen stores in harbor seals: effects of age, mass, and body composition. Physiol Biochem Zool 78: $1057-1068$

Burns JM, Lestyk KC, Folkow LP, Hammill MO, Blix AS (2007) Size and distribution of oxygen stores in harp and hooded seals from birth to maturity. J Comp Physiol B 177: $687-700$

Davis RW, Fuiman LA, Williams TM, Le Boeuf BJ (2001) Three-dimensional movements and swimming activity of a northern elephant seal. Comp Biochem Physiol A 129: $759-770$

Gjertz I, Kovacs KM, Lydersen C, Wiig Ø (2000) Movements and diving of bearded seal (Erignathus barbatus) mothers and pups during lactation and post-weaning. Polar Biol 23: 559-566

> Greaves DK, Hughson RL, Topor Z, Schreer JF, Burns JM, Hammill MO (2004) Changes in heart rate variability during diving in young harbor seals, Phoca vitulina. Mar Mamm Sci 20:861-871

> Hausdorff JM, Zemany L, Peng CK, Goldberger AL (1999) Maturation of gait dynamics: stride-to-stride variability and its temporal organization in children. J Appl Physiol 86:1040-1047

Hill AV (1950) The dimensions of animals and their muscular dynamics. Sci Prog 38:209-230

Hill AV (1964) The efficiency of mechanical power development during muscular shortening and its relation to load. Proc R Soc Lond B Biol Sci 159:319-324

Hjelset AM, Andersen M, Gjertz I, Lydersen C, Gulliksen B (1999) Feeding habits of bearded seals (Erignathus barbatus) from the Svalbard area, Norway. Polar Biol 21: 186-193

Irschick DJ (2000) Effects of behaviour and ontogeny on the locomotor performance of a West Indian lizard, Anolis lineatopus. Funct Ecol 14:438-444

> Kovacs KM, Lydersen C, Gjertz I (1996) Birth-site characteristics and prenatal molting in bearded seals (Erignathus barbatus). J Mammal 77:1085-1091

> Krafft BA, Lydersen C, Kovacs KM, Gjertz I, Haug T (2000) Diving behaviour of lactating bearded seals (Erignathus barbatus) in the Svalbard area. Can J Zool 78:1408-1418

LeBoeuf BJ, Morris P, Reiter J (1994) Juvenile survivorship of northern elephant seals. In: Le Beouf BJ, Laws RM (eds) Elephant seals: population ecology, behavior, and physiology. University of California Press, Berkeley, CA, p 121-136

Lydersen C, Kovacs KM (1999) Behaviour and energetics of ice-breeding, North Atlantic phocid seals during the lactation period. Mar Ecol Prog Ser 187:265-281 
Lydersen C, Hammill MO, Kovacs KM (1994) Diving activity in nursing bearded seal (Erignathus barbatus) pups. Can J Zool 72:96-103

Lydersen C, Kovacs KM, Hammill MO, Gjertz I (1996) Energy intake and utilisation by nursing bearded seal (Erignathus barbatus) pups from Svalbard, Norway. J Comp Physiol [B] 166:405-411

Madsen PT, Kerr I, Payne R (2004) Echolocation clicks of two freeranging, oceanic delphinids with different food preferences: false killer whales Pseudorca crassidens and Risso's dolphins Grampus griseus. J Exp Biol 207: 1811-1823

Marshall CD, Amin H, Kovacs K, Lydersen C (2006) Microstructure and innervation of the mystacial vibrissal follicle-sinus complex in bearded seals, Erignathus barbatus (Pinnipedia: Phocidae). Anat Rec Part A 288:13-25

Noren SR, Biedenbach G, Edwards EF (2006) Ontogeny of swim performance and mechanics in bottlenose dolphins (Tursiops truncatus). J Exp Biol 209:4724-4731

Rea LD, Costa D (1992) Changes in standard metabolism during long-term fasting in northern elephant seal pups (Mirounga angustirostris). Physiol Zool 65:97-111

Sato K, Mitani Y, Cameron MF, Siniff DB, Naito Y (2003) Factors affecting stroking patterns and body angle in

Editorial responsibility: Rory Wilson,

Swansea, UK diving Weddell seals under natural conditions. J Exp Biol 206:1461-1470

Sato K, Watanuki Y, Takahashi A, Miller PJO and others (2007) Stroke frequency, but not swimming speed, is related to body size in free-ranging seabirds, pinnipeds and cetaceans. Proc R Soc Lond B Biol Sci 274:471-477

Sato K, Daunt F, Watanuki Y, Takahashi A, Wanless S (2008) A new method to quantify prey acquisition in diving seabirds using wing stroke frequency. J Exp Biol 211: $58-65$

> Watanabe Y, Baranov EA, Sato K, Naito Y, Miyazaki N (2006) Body density affects stroke patterns in Baikal seals. J Exp Biol 209:3269-3280

Webb PW (1988) Simple physical principles and vertebrate aquatic locomotion. Am Zool 28:709-725

Weihs D (1974) Energetic advantages of burst swimming of fish. J Theor Biol 48:215-229

> Williams TM, Davis RW, Fuiman LA, Francis J and others (2000) Sink or swim: strategies for cost-efficient diving by marine mammals. Science 288:133-136

Wilson RP, Liebsch N (2003) Up-beat motion in swinging limbs: new insights into assessing movement in free-living aquatic vertebrates. Mar Biol 142:537-547

Submitted: August 4, 2008; Accepted: October 29, 2008 Proofs received from author(s): March 28, 2009 